\title{
A inserção de mulheres em programa de alfabetização: motivações discentes
}

\author{
Rosângela Pedralli* \\ Laiana Abdala Martins **
}

\begin{abstract}
Resumo
É objeto deste artigo compreender as motivações das mulheres inseridas em entornos grafocêntricos em relação ao processo de alfabetização formal. Norteia o estudo a seguinte questão: o que motiva as mulheres participantes deste estudo a recorrerem a uma instituição escolar a fim de participarem de um programa de alfabetização? Teoricamente, embasam este trabalho, um estudo de caso do tipo etnográfico, autores como Graff (1994), Britto (2003, 2004), Stromquist (2005), entre outros. Os resultados apontam para uma convergência apenas parcial entre os propósitos desses programas e tais motivações.
\end{abstract}

Palavras-chave: Alfabetização. Educação de Jovens e Adultos. Motivações.

\footnotetext{
* Doutora em Linguística Aplicada, pela Universidade Federal de Santa Catarina (UFSC). Professora do Departamento de Língua e Literatura Vernáculas na mesma universidade (UFSC).

** Mestra em Linguística Aplicada, pela Universidade Federal de Santa Catarina (UFSC)

PERSPECTIVA, Florianópolis, v. 35, n.3, p. 738-757, jul./set.. 2017 


\section{Introdução}

O presente artigo tem como objeto as motivações subjacentes à participação em processo de alfabetização $^{1}$ formal explicitadas por três mulheres, moradoras de Florianópolis/SC, inseridas no mercado de trabalho e participantes do Curso de Educação de Jovens e Adultos - I Segmento, realizado pela Prefeitura Municipal de Florianópolis. O campo de pesquisa foi, então, uma escola da rede municipal do norte da ilha, nesse município.

Do ponto de vista metodológico, este artigo é fruto de uma vivência de cinco meses (de abril a agosto de 2011) no espaço escolar em que se deu a pesquisa, na forma de estudo de caso de tipo etnográfico (ANDRÉ, 1995), contando com interações mais pontuais com as três mulheres participantes do estudo, incluindo seus espaços domiciliares. Essa vivência acabou por gerar um conjunto de dados composto, principalmente, por notas de campo, entrevistas e imagens fotográficas.

Com este trabalho - fundamentado teoricamente nos Estudos do Letramento -, temos por objetivo produzir inteligibilidades acerca da questão que segue: o que motiva as mulheres participantes deste estudo a recorrerem a uma instituição escolar a fim de participarem de um programa de alfabetização? Isso por entendermos que a decisão, na idade adulta, pela inserção em um programa de alfabetização na modalidade Educação de Jovens e Adultos ${ }^{2}$ tende a responder a motivações pessoais de toda ordem, muitas vezes derivadas de premências de trabalho, outra vezes decorrentes de razões familiares e, não raro, fruto de questões mais amplas, ligadas à macroinserção social ou a desdobramentos da ontologia humana. Depreender essas motivações seguramente não é uma tarefa simples, mas nos arriscamos a ela por entendermos que dessa depreensão dependem, em boa medida, as discussões acerca da necessidade de que as ações de escolarização sejam desenvolvidas à luz das vivências de alunos (alunas, no caso).

\section{Vivências com a escrita por sujeitos historicizados: as bases epistemológicas}

A fundamentação epistemológica do presente artigo é de base histórico-cultural; dessa forma, são evocados(as) estudiosos(as) que, em nosso entendimento, compartilham uma concepção de língua não como um aprendizado que requer exercício, mas como uma construção cultural que tem lugar na história humana. Consiste, desse modo, em um olhar focado nas relações intersubjetivas, considerando que os sujeitos se constituem nas relações com o outro, por meio da língua, marcando-se 
identitariamente como pertencentes a determinado grupo social, condição em que eles incidem sobre o mundo e se deixam incidir por ele (BRITTO, 2012).

Trata-se, assim, de uma convergência que concebe a língua como necessariamente social, instrumento psicológico que faculta a instituição de relações humanas. E, nessa compreensão, em que a língua não é tomada na imanência e tampouco como conjunto de formas disponíveis independentemente da ação e do trabalho humanos, erige-se a representação de língua como objeto social, fundamentalmente ligada às identidades de grupos sociais e às subjetividades que se constituem no trânsito/deslocamento/inserção em diferentes espaços culturais por meio das relações intersubjetivas que as pessoas estabelecem nas diferentes esferas de atividade humana.

Entender língua desse modo implica ressignificações da forma como compreendemos identidade (PONZIO, 2008, 2009) e cultura escrita, as quais são, em sua essência, à luz dessa compreensão de língua, historicamente construídas e, como construções humanas, dão-se na historicidade, de modo circunstancial, e pressupõem encontros (PONZIO, 2010). Assim, entendem-se que

[...] a palavra subsiste apenas no encontro com a outra palavra. A bem da verdade não se trata de uma relação entre dois, entre dois sujeitos, entre duas palavras, como se houvesse antes dois sujeitos, as duas palavras e em seguida a relação entre elas, o encontro. É exatamente a relação, o encontro que faz existir a palavra como outra palavra; esta é por esta relação, não existe antes, não existe fora disso. (PONZIO, 2010, p. 39).

Trata-se, pois, de encontros, que tanto nos modificam, como modificam o outro, deslocando no que respeita ao objeto deste estudo - configurações efemeramente cristalizadas acerca da cultura escrita e das nossas representações sobre o mundo no que concerne às práticas de letramento. Esses deslocamentos, no entanto, resistem de modo mais ou menos efetivo a configurações macrossociológicas (PONZIO, 2008, 2009), que tendem a cercear nossas ações, atendendo a demandas imediatas de uma sociedade urbano-industrial que, em boa medida, tolhem muitas das possibilidades de relação entre nós e o outro por meio da escrita (BRITTO, 2012).

Com base em Ponzio (2008, 2009), entendemos que nossas ações não raro são submetidas a cerceamentos macrossociológicos que nos encapsulam em categorias dicotômicas como brancos ou negros, homens ou mulheres, jovens ou velhos, conferindo ao conceito de identidade perspectivas individualista e funcionalista - entendida esta última como a servilidade a um mercado global - e descurando da condição fundamental de relação com a alteridade para o delineamento da identidade, sem o que esse conceito se esvazia. Importa, pois, considerarmos que os usos da língua - aqui, no 
âmbito das práticas de letramento - trazem consigo deslocamentos, por conta de nossa ação com o outro e com o mundo, o que, por sua vez, dá-se pela mediação da linguagem (VIGOTSKI, 2007).

Desse modo, compartilhamos com Ponzio (2008, 2009) a compreensão de que lidar com a identidade - neste caso, feminina -, sob o ponto de vista das já mencionadas categorias macrossociológicas, implica lidar com indivíduos abstratos, e não com sujeitos singulares, comportamento em relação ao qual o autor se contrapõe. Eis, na sequência, a apresentação do programa de alfabetização locus do presente estudo.

\section{0 programa de alfabetização em tela: configuração sucinta e objetivos}

A exemplo dos muitos programas endereçados à parcela jovem e adulta da população, o Curso de Educação de Jovens e Adultos da Prefeitura Municipal de Florianópolis/SC equivale ao Ensino Fundamental e foi elaborado tendo em vista a premissa de que as pessoas que estudam na EJA procuram um curso diferente, visto que

[...] a maioria trabalha, tem família, muita responsabilidade, não pôde estudar na escola na época da infância e da adolescência. Algumas pessoas tiveram um passado difícil e não puderam concluir o ensino fundamental na idade apropriada. Portanto, a proposta da EJA tem que ser diferente e adequada ao seu grupo. (FLORIANÓPOLIS, 2010a, p. 1).

Podem se inscrever nesse curso pessoas com quinze anos ou mais. Quanto à formação das turmas e a criação dos próprios núcleos de EJA, de acordo com o Artigo $7^{\circ}$ da Resolução ${ }^{\circ} 2$, de 13 de dezembro de 2010, editada pelo Conselho Municipal de Educação (CME) de Florianópolis, que estabelece Normas Operacionais Complementares em conformidade com o Parecer $n^{\circ}$ 6, de 20 de outubro de 2010, de autoria da Câmara de Educação Básica (CEB) do Conselho Nacional de Educação, e com as Resoluções CNE/CEB n 2, de 19 de maio de 2010, e no 04, de 13 de julho de 2010, que instituem as Diretrizes Gerais e Operacionais para a Educação de Jovens e Adultos

Caberá à Secretaria Municipal de Educação, conforme interesse e necessidade, implantar os

Núcleos de Educação de Jovens e Adultos para atender a demanda.

$\S \mathbf{1}^{\mathbf{0}}$ As turmas de Educação de Jovens e Adultos serão constituídas conforme as seguintes orientações:

I - mínimo de 15(quinze) alunos para constituição de turma;

II - o primeiro segmento não poderá ultrapassar 25 (vinte e cinco) alunos frequentes;

III - o segundo segmento não poderá ultrapassar 30 (trinta) alunos frequentes;

IV - em caso excepcional, reconhecida as peculiaridades da clientela do primeiro segmento e interesse da SME [Secretaria Municipal de Educação], poderá ser 
autorizada a criação de turma com número inferior a 15 (quinze) alunos. (FLORIANÓPOLIS, 2010b).

Durante o curso, são realizadas pesquisas em pequenos grupos. Estas pesquisas originam-se de problemáticas do interesse e da necessidade dos alunos. Tanto nas aulas como no processo de construção que dá origem à pesquisa, é objetivo motivar a leitura diária. Além de estímulo à leitura, o trabalho, nessa perspectiva, objetiva facultar ao aluno: identificar e avaliar suas próprias necessidades de conhecimento atuais, buscando soluções; problematizar e debater sobre o que estudar, sob que justificativa, sobre quais as dificuldades e avanços encontrados nas atividades realizadas, acerca das regras de convivência, regimento, direitos e deveres; autoavaliar-se responsavelmente; saber identificar, avaliar, valorizar e exercer seus direitos e deveres como cidadão; saber ler e se expressar com clareza, concisão, coerência, autonomia e fundamentação nas diversas formas de expressão humana: através de textos de vários tipos, dramatizações, representações, apresentações, soluções matemáticas, etc.; entre outras questões.

Na seção seguinte serão analisadas as motivações para a inserção de cada mulher em classes de alfabetização, tendo presente a fundamentação epistemológica deste estudo e a configuração e os objetivos do presente Curso.

\section{A importância da representação positiva decorrente da experiência primeira com a escolarização}

As considerações das participantes de pesquisa acerca das motivações que as levaram a participar de um programa de alfabetização remontam à experiência primeira com a escolarização, ainda na infância. Isso, em nosso entendimento, precisa ser analisado na medida em que uma representação favorável desse processo parece resultar em anseio por retorno à escola ou não. Na sequência, arriscamos postar longos excertos que dão conta desse recorte de historicidade que converge com nosso interesse analítico aqui; feito o registro, empreenderemos a análise.

(01) $\mathrm{Eu}$, na realidade, parei de estudar porque, sabe, quando a gente é adolescente, a gente quer ter o dinheirinho da gente e, como antigamente não é como agora, os pais não deixavam a gente estudar de noite, então eles disseram pra escolher: "ou tu vai trabalhar ou, se não, estudar de dia". [...] daí eu parei de estudar, comecei a trabalhar, daí depois eu casei, daí mesmo eu nunca mais voltei. (M., 2011, informação oral ${ }^{3}$ ).

(02) Daí, pra fazer o ginásio, na época, era em outra cidade, tudo longe. [...] a minha mãe sempre dizia: "Ah! Porque os meninos não vão estudar mais por isso, por aquilo". 
[...] daí a gente morava em cidadezinha bem distante de cidade grande para estudar, e daí minha mãe [pausa], pelo meu pai até eu ia, mas como naquele tempo as meninas não podiam sair dos olhos da mãe, né [pausa], daí saía já ia namorar, naquele tempo nem pensava em namoro, nada, né, mas o meu irmão mais velho, ele foi, né, foi, estudou, hoje em dia ele é professor, ele é tudo, mas ele foi a fundo mesmo estudando (E., 2011, informação oral ${ }^{4}$ ).

(03) Estudei pouco, não tive tempo de aprender muito e também já comecei tarde, porque, naquele tempo, eu lembro que a gente tinha que caminhar quilômetros e quilômetros pra poder ir até o colégio, e era difícil, porque lá caía muita geada, muito frio, mas mesmo assim a gente ainda ia. Mas claro que, com temporal, chuva, essa coisa toda, não tinha como, então passava semanas sem ir pro colégio. E o que tornava mais difícil é que não tinha ônibus pra levar e trazer, a gente tinha que ir caminhando. [...] eu lembro que, na época de plantação, os pais, naquela época, precisavam dos filhos, então a gente ajudava. Eles tinham muita plantação de arroz, feijão, milho, que a gente comia tudo essas coisas, invernava para comer depois. E, depois, numa certa época, quando era época do fumo, então tinha plantação de fumo, então daí precisava das crianças pra botar a semente pra eles irem plantando, que era a mudinha, precisava da gente pra tudo naquela época, pra ajudar a cuidar dos menores, até mesmo os maiorzinhos faziam comida pra poder os pais continuar a trabalhar. [...] Também a gente, com muita falta de informação naquela época, ia pra escola e voltava, não tinha aquela coisa do pai dizer "estuda", que nem a gente hoje em dia, "estuda, faz isso faz aquilo, olha eu quero tu com nota boa", sentar com o filho. [...] depois voltei pro colégio pra tentar de novo, depois de mais adulta, e não tive condições de terminar de novo por causa da gravidez, porque eu era muito novinha e inchei demais. Eu tinha que limpar a casa, lavar a roupa e cozinhar, que eu trabalhava fora também, grávida, daí tive que parar. (MG., 2011, informação oral ${ }^{5}$ ).

Os trechos (01), (02) e (03) sugerem um entendimento, por parte dessas mulheres, de que a escola tem um valor em si mesma ou, por outro lado, suscitam uma supervalorização da instituição escolar. As participantes de pesquisa evidenciam, nas falas, a incorporação desse discurso, que também se encontra subjacente à maioria das iniciativas de alfabetização em massa e acaba por ser incorporado pelo senso-comum.

Com relação ao papel da escola e ao espaço da alfabetização, Graff (1994) afirma que os lugares da alfabetização e da escolarização não podem ser entendidos nem como sacrossantos nem como muito bem compreendidos. Para o autor, ocorre que estamos familiarizados com a centralidade da alfabetização de tal forma que reorientamos nosso pensamento a respeito dos papéis e da relevância da alfabetização e da escolarização, processo em que tendemos a superestimar sua influência no delineamento das relações sociais. Segundo o autor, “[...] nós supervalorizamos a alfabetização por si mesma e, ao fazê-lo, nós a removemos de seu contexto sócio-cultural" (GRAFF, 1994, p. 29). Trata-se, aqui, tal qual adverte Britto (2004), de depurar os ganhos ou perdas da/com a alfabetização de suas contingências socioeconômicas e políticas. 
Compartilhamos com esses autores a compreensão de que perpassam a alfabetização fatores de natureza econômica, política e social que não podem ser denegados, sob pena de atribuirmos ao domínio do sistema de escrita alfabética e aos usos a que esse sistema se presta, em si mesmos, uma dimensão socialmente redentora, o que termina por delegar ao indivíduo - secundarizando especificidades de sua inserção sociocultural e econômica - a culpa pelo fracasso ou os louvores decorrentes do sucesso na conquista de um lugar social em seu tempo histórico. Entendemos, aqui, fracasso e sucesso à luz de expectativas sociais historicamente construídas a respeito do que seja ter qualidade de vida contemporaneamente.

Nesse sentido, o acesso à alfabetização não é visto, por parte de muitos analfabetos e alfabetizandos, como um direito adquirido ou a partir de uma perspectiva coletiva; é, na maioria das vezes, concebido pelo mérito atribuído ao esforço individual (GALVÃO; DI PIERRO, 2007). Essa relação fica nítida nos trechos dos excertos imediatamente anteriores. Neles - “(01) Eu, na realidade, parei de estudar porque, sabe, quando a gente é adolescente, a gente quer ter o dinheirinho da gente e, como antigamente não é como agora, os pais não deixavam a gente estudar de noite, então eles disseram pra escolher 'ou tu vai trabalhar ou, se não, tu estuda de dia' (M., 2011), por exemplo -, o analfabetismo não é concebido como um processo de exclusão social ou de violação dos direitos coletivos, mas é visto pelo jugo individual de desvio ou fracasso, que, por sua vez, promove repetidos episódios de discriminação e humilhação causadores de sofrimento e de culpa e vergonha aos analfabetos/alfabetizados de nível rudimentar. Deixar de estudar, aqui, é ato interpretado por $M$. como resultado de uma opção sua, descolada das contingências sociais.

As remissões à condição de agente/responsável pela desistência, e não como vítima de um construto social mais amplo, que acaba por impedir ou dificultar a permanência desses sujeitos no processo de escolarização, aparecem nas falas na forma de culpabilização de diferentes naturezas: autoculpabilização, culpabilização de pessoas próximas (os pais, por exemplo) ou, ainda, de questões bem estritas, que dificultam/impedem a mobilidade dessas pessoas, tais como distanciamento geográfico da escola, questões climáticas, etc. Mais uma vez, o olhar interpretativo dos sujeitos não contempla a macroestrutura social em que tais fatores se tornam obstáculos à frequência à escola e ao aprendizado efetivo.

No fragmento (01), são visíveis três movimentos de culpabilização: autoculpabilização, quando M. afirma ter parado de estudar porque, quando era adolescente, queria ter seu próprio dinheiro; culpabilização de pessoas próximas, quando essa mulher afirma que antigamente os pais não 
permitiam que os filhos estudassem à noite; e culpabilização atribuída a questões bem estritas, que dificultam/impedem a mobilidade: estudar à noite e o casamento, em alguma medida, estão implicados nessa questão.

A fala de E., (02), é representativa de dois desses movimentos de culpabilização: culpabilização de pessoas próximas, quando a participante da pesquisa afirma que foi a mãe quem não permitiu a ela e aos irmãos continuarem os estudos, o que carreia em sua subjacência o peso que historicamente recai sobre as mulheres quanto ao cuidado com a integridade dos filhos, sobretudo das filhas, seguida pela informação de que o pai não os impedira, ao que parece, apoiara de modo mais assertivo a continuidade dos estudos; e culpabilização atribuída a questões bem estritas, que dificultam/impedem a mobilidade, na passagem em que $E$. menciona que o fato de morarem em uma cidade muito distante do local em que poderiam ter dado continuidade aos estudos dificultou sobremaneira a conclusão do processo de escolarização.

Da fala de $M G$., em (03), é depreensível pelo menos um desses movimentos de culpabilização: culpabilização atribuída a questões bem estritas, que dificultam/impedem a mobilidade, mas que apresenta diferentes desdobramentos, como por exemplo: a culpabilização atribuída a questões geográficas, quando a participante de pesquisa afirma lembrar-se de precisar locomover-se a pé por longas distâncias para ir à escola mais próxima, em razão da falta de ônibus para tal finalidade; questões climáticas, evocadas no momento em que $M G$. relembra ter muitas dificuldades em frequentar as aulas nos períodos de chuva, frio e geada; além de outros fatores. Assim, elementos de natureza física e espacial são tomados, em si mesmos, como obstáculos ao aprendizado, quando, na verdade, somente o são em razão de contingências socioeconômicas e políticas mais amplas, entre as quais estão a falta de infraestrutura institucionalmente construída para tanto.

Tendo em vista os objetivos da discussão aqui proposta, não nos interessa abordar as causas estritas que favoreceram a evasão escolar, tampouco os movimentos de culpabilização evidenciados nas falas das participantes de pesquisa (PEDRALLI; CERUTTI-RIZZATTI, 2013). Nossa análise, nesse sentido, presta-se a demonstrar que, assim como afirma Britto (2004), essa supervalorização do plano técnico-individual que subjaz à fala dessas pessoas escamoteia os problemas políticos e sociais implicados nos modos de produção, circulação e apropriação do conhecimento. Para ele, o debate sobre alfabetização e letramento só ganha sentido se forem consideradas, no âmbito da educação e da aprendizagem, as desigualdades, as diferenças e as disputas que se dão no bojo das estruturas sociais. 


\section{As motivações para a reinserção em instituição escolar via programa de alfabetização}

Considerando especificamente, então, as motivações de tais alfabetizandas para o retorno à escolarização, as participantes de pesquisa elencam motivações de diferentes naturezas, tais como: vontade de voltar para escola, que perdurou durante a vida toda dessas mulheres, ao que parece, derivada de uma representação favorável do processo primeiro de inserção escolar; e/ou vivência estreita com familiar ou pessoa próxima alfabetizada (MACIEL; LUCIO, 2010); metodologia de trabalho diferenciado por parte do programa de escolarização; interesse/necessidade de ampliar o conhecimento lexical e gramatical nos usos da língua e as habilidades interacionais; ou, simplesmente, sair de casa e ter algumas horas de relaxamento (STROMQUIST, 2005).

Kleiman (2001), nesse sentido, propõe que as motivações dos alfabetizandos para a inserção em processo de escolarização, em linhas gerais, obedecem a duas frentes, a saber: são de foro íntimo, individual, e de foro externo, social, o que parece se confirmar a partir das informações arroladas pelas participantes.

(04) Eu sempre tive vontade de voltar a estudar, mas claro que agora a dificuldade é diferente, claro que o que me incentivou mais é que agora é pesquisas, se for pra mim começar, como é normalmente inglês, português, química, essa coisas, daí eu, lógico, vou me apertar bastante, mas não que eu não tenha vontade de estudar. Mas, graças a Deus, eu tô gostando, tô adorando[...] (M., 2011).

O trecho da fala de $M$. remete à importância ou ao encorajamento que uma metodologia de trabalho diferenciada, como a adotada pela Prefeitura Municipal de Florianópolis, pautada nas pesquisas, que prescinde dos domínios dos conteúdos escolares formais, confere à reinserção no processo de ensino institucional. Isso porque é de se esperar que, depois de muitos anos de afastamento da escola, os sujeitos, de forma geral, grupo do qual $M$. não é exceção, tenham se desvinculado dos conteúdos escolares pela não significação deles em sua vida prática. Por outro lado, os conteúdos com aplicação prática e que tenham significado em relação às vivências dessas pessoas, dos quais, em tese, elas se apropriam durante o processo de pesquisa, parecem corresponder, nessa clientela, a uma demanda prototípica. 
(05) Eu sempre tive vontade de estudar, mas eu tive muito incentivo, assim de me incentivar mesmo, da minha filha, essa que mora comigo, a outra filha também. Porque essa aqui sempre gosta de estudar, ela tá sempre [pausa], então ela "vai mãe, vai", só que tinha receio [pausa]. Que nem eu te falei de matemática, de português, daí eu achei que eu ia, né [pausa]. Daí ela explicou que agora era diferente na EJA, que era as pesquisas, daí "então tá". (M., 2011).

No excerto (05), $M$. pontua a reluta inicial em voltar à escola. Nesse sentido, ela reforça a importância de uma metodologia de trabalho diferenciada como encorajadora do retorno, mas, principalmente, aponta para a influência decisiva da filha nesse processo. Tal influência da filha se dá em relação a diferentes aspectos. O primeiro deles é a inserção da mãe na cultura letrada. Isso se dá a partir de várias ações da filha, sejam elas objetivas ou mais subjetivas: construção de um acervo de livros, obras de arte e CDs com repertório musical erudito; disponibilização e acesso (KALMAN, 2003), em casa, de/a revistas e jornais compartilhados com a mãe; incentivo à leitura, em detrimento de acompanhamento de telenovelas, por exemplo; e atribuição de valoração substantiva a essas práticas, ao afirmar que são mais proveitosas se comparadas a outras manifestações da cultura massiva; estímulo explícito a leituras e coconstrução de caminhos para leituras de textos em gêneros mais difíceis, que resultam em desenvolvimento de novas práticas de letramento por parte da mãe; e, por fim, pelo estímulo de que se reveste a participação da filha em práticas de letramento dessa natureza ${ }^{6}$, entre outras questões.

Outro processo de influência da filha se estabelece no momento que ela encoraja a mãe diretamente a retomar o processo educativo formal, do qual se evadiu ainda na infância. Isso é explicitado na fala da participante de pesquisa, quando relembra as palavras da filha - "(05) [...] então ela 'vai mãe, vai'”. A importância desse encorajamento também é demonstrada quando a mãe menciona que foi a filha quem a informou sobre a metodologia diferenciada adotada pelo programa em questão - “(05) [...] daí ela explicou que agora era diferente na EJA, que era as pesquisas”. Essa passagem sugere especialmente a importância que o familiar, nesse caso a filha, teve na busca por informações sobre o programa e no repasse delas à alfabetizanda.

Essas implicações da influência da filha no retorno à escolarização por parte de $M$. convergem com o que defendem Maciel e Lúcio (2010) acerca das relações estabelecidas entre pessoas que dominam e utilizam autonomamente o sistema de escrita alfabética e adultos analfabetos ou em processo de alfabetização. Para as autoras, a importância da intervenção de membros familiares no processo de apropriação da leitura e da escrita não pode ser denegada.

E., por sua vez, relata motivações de outra natureza. Para ela, a metodologia de trabalho adotada pelo programa e as possíveis implementações de conhecimentos lexicais, gramaticais e de habilidades 
interacionais parecem não ter tanta relevância. Na fala de E., são flagrantes três aspectos: a representação favorável que alimenta em relação à escolarização desde a infância, o que a fez nutrir um desejo de retorno à escola ao longo de toda vida; a influência determinante de familiar para tal retorno; e o componente psicológico de que se revestiu essa reinserção escolar, na medida em que essa vivência escolar constitui uma das poucas oportunidades de relaxamento (STROMQUIST, 2005) que E. tem diante de uma rotina laboral exaustiva e de uma historicidade marcada pelo sofrimento. A seguir, transcrevemos um longo excerto da entrevista de $E$. e, mesmo cientes da impropriedade de fazê-lo com esta extensão, arriscamos a opção em nome da relevância que atribuímos ao seu conteúdo.

(06) [...] porque, assim, eu casei com dezenove anos, então, assim, logo casei, estava grávida, né? E a vontade de estudar, e a vontade de estudar. E eu também, assim, antes dos dezenove anos, eu também pensava muito em estudar, mas nunca dava certo. Daí, com dezessete anos, fui trabalhar [fora], tudo, assim, e daí não deu certo mesmo. Daí, casei, tive os filhos, e o marido sempre bebendo e [com] ciúmes, assim, né, não deixava [pausa]. Mas eu pensava, eu dizia: "mãe, eu tô pensando em estudar, mas daí como vou estudar e cuidar das crianças?" O marido, às vezes, ia trabalhar e eu não podia nem sair de casa por causa do ciúme. Daí, ficou, passou o tempo e aquela vontade de estudar. Vim embora pra cá, pra Florianópolis, e aquela vontade de estudar [pausa]. Aí, quando foi que eu peguei meus quarenta anos e foi os trinta tudo [pausa], quando chegou nos quarenta e sete, eu comentei com a minha filha: "J. [nome da filha], eu queria tanto estudar", porque eu via as meninas, as mulheres estudando aqui, né? [...] Aí, quando foi com cinquenta anos já, daí eu falei pra minha filha: "a mãe tem uma vontade de estudar". Daí ela conversou como uma amiga, que disse: "lá no colégio assim e assim tem a EJA, e a tua mãe que quer estudar, isso e aquilo", e daí ela ficou, né, botou aquilo na cabeça e falou pra mim, né, ela disse: "mãe, amanhã a mãe fica pronta aí quando as crianças forem embora que nós vamos lá na escola, que a mãe vai começar a estudar". Meu genro e minha filha vieram aqui comigo e fizeram a minha matrícula, né [pausa] [...] Daí eu comecei a estudar, né, vinha aqui, me sentia até meio sem jeito no meio da [pausa] eu olhava assim no meio dos adolescentes, ficava olhando, olhando, mas foi tudo bom, eu gostei. O marido, no começo [pausa], Ai!, meu Deus do céu! Até hoje, é uma luta pra eu estudar. [...] Daí meu filho e minha filha me deram força, daí eu falei: "depois de vovó, eu vou estudar pra ter uma coisa pra contar pra neta depois, né”. Daí ela veio aqui comigo, a gente fez a matrícula. Ai!, eu não via a hora de começar a estudar, não via [pausa]. (E., 2011).

A longa passagem da entrevista de $E$. é bastante ilustrativa de sua vontade de retornar à escola, vontade que perpassou a vida inteira da participante de pesquisa, possivelmente como decorrência de uma representação favorável em relação à escolarização na infância e, também, por um movimento, por parte de E., de valoração da escolarização em si mesma (GRAFF, 1994). Vóvio (2010), nesse sentido, afirma que é histórica no Brasil a compreensão da alfabetização como um valor, superdimensionandose o domínio da escrita em si mesmo, com assepsia da dimensão social de que se reveste; a importância da escrita e da imprensa na vida dos indivíduos e da sociedade; a exigência de habilidades com a escrita 
para inserção efetiva em contexto social; a atribuição à alfabetização e à escolarização de caráter delimitador de civilização, o que encontra convergência nas contraposições de Street (1984) àquilo que nomeou como modelo autônomo de letramento. Não se trata, aqui, de colocar em xeque a importância da escolarização na vida humana; trata-se de chamar atenção para a forma imanente e redentora como a escolarização historicamente tem sido vista em muitos entornos, especialmente naqueles de vulnerabilidade social.

É visível, tanto em (05) quanto em (06), a importância fundamental que os familiares de $E$. (filha e genro) tiveram nesse processo longo que se deu entre a vontade de retorno à escola, ainda na adolescência, e a concretização dela, aos cinquenta anos. Importa mencionar que tal importância tem natureza diferente da evidenciada no testemunho de $M$.. Embora, nos dois casos, os familiares tenham importância fulcral na retomada do processo de escolarização, no caso de $M$., a interferência da filha, como discutimos anteriormente, tem componentes como a construção/implementação de determinadas práticas de letramento por parte da mãe e a importância que o familiar alfabetizado (filha) teve ao conseguir informações acerca da nova metodologia de ensino adotada para EJA nessa escola, o que instigou $M$. a retornar efetivamente; enquanto para $E$. a interferência da filha (e do genro) tem uma nuance mais prática: é ela quem decide o dia que a mãe retornará à escola, é ela quem informa à mãe sobre os dias e os horários em que se realizam as aulas e é ela, inclusive, quem leva a mãe à escola e realiza a matrícula.

(07) Ela [a filha] falou: "ah, mãe é de segunda a sexta", eu "tá bom, fillha". E me sinto bem, bem mesmo e até, assim, a minha vida assim, professora, mudou bastante, porque eu era uma pessoa sempre muito fechada, mesmo quando trabalhava fora ou cuidando de criança, às vezes eu chegava à noite, eu tava tão cansada, eu pensava assim "meu Deus, como é que eu vou estudar?". [...] No começo, antes de eu fazer a matrícula, eu dizia "Ai!, filha, vai ser um cansaço também ir pra escola", e ela "não, mãe, vai ser bom pra mãe, vai ser até uma terapia pra mãe isso dấ". [...] Então, professora, quando eu comecei a vir assim, eu via que as coisas estavam mudando, comecei me enturmar com as pessoas, conversar ao invés de ficar em casa, assim, com aquele clima tão ruim. [...] porque às vezes eu tava em casa, eu não queria nada, só dizia assim "ai! hoje eu vou só cuidar dessas crianças e não quero saber de nada só quero dormir”, só queria ficar dentro de casa, enfiada dentro de casa e eu tava me sentindo mal assim. As gurias [amigas de E.] diziam assim "ai!, é até perigoso pegar uma depressão com a vida que tu leva", porque a minha vida, 31 anos [de casamento], não é fácil, casada, professora, é uma vida triste mesmo, sabe, uma vida que ninguém queria ter [...]. (E., 2011).

No trecho (07), parece-nos bastante evidente o componente terapêutico que as vivências na escola representam, assim como afirma Stromquist (2005). As motivações dos alunos na busca por um programa de alfabetização formal, segundo a autora, tendem a ser diferentes das manifestadas pelos idealizadores dos programas, o que é evidenciado na fala de E. Eis, no caso dessa mulher, as questões 
relacionadas à ontologia humana a que fazíamos menção anteriormente; e da escola como função de convivência, inclusive com desdobramentos terapêuticos para a vida concreta das relações.

$M G$., por sua vez, reafirma a concepção, já mencionada no caso de $E$., de a escola ter um valor em si mesma (GRAFF, 1994), quando afirma, em (08), que "[...] a escola é o eixo, sim, é a base, a ler e a escrever, a falar com as pessoas, a falar corretamente, sabendo o que tá falando, e não falar ignorantemente, sem saber o que está dizendo" (MG., 2011). Entendemos, subjacente a essa fala de $M G$., ainda, a importância que as implementações nas habilidades interacionais e nos conhecimentos lexicais e gramaticais parecem ter para essa participante de pesquisa.

No trecho (09) - "Até hoje, eu continuo tentando levantar a cabeça; a minha saída foi o colégio porque eu vejo assim que a única coisa que ainda me dá uma luz é que eu estou aprendendo um pouco [...]” (MG., 2011) - é evidenciado, assim como no caso de E., o componente psicológico - ou ousamos entender isso em uma dimensão mais ampla, de natureza ontológica - do qual pode se revestir a vivência em esfera escolar, no sentido de garantir ao alfabetizando algumas horas de relaxamento (STROMQUIST, 2005).

MG (2011). registra em sua fala - “(10) [...] as pessoas que sabem mais, quando estão falando com você, elas analisam o que você está falando, e sempre tem aqueles que pensam “ah!, é burra, é burra, é burra, é ignorante, ignorante, ignorante, essa é ingênua mesmo, não sabe nem o que tá dizendo, então vamos nos aproveitar"'-, também os episódios de preconceito a que se viu submetida e a internalização da condição de subalternidade conferida ao não alfabetismo pleno em sociedades grafocêntricas, o que acaba por impeli-la a retornar à escola. A esse respeito, Galvão e Di Pierro (2007) afirmam que tal é a valorização da alfabetização nesse âmbito grafocêntrico que, hoje, não ler e não escrever são comportamentos equiparados a outras marcas distintas da pobreza, uma alegoria da condição de subalternidade. Estão implícitas nesse trecho da fala de MG. questões identitárias, tal qual defende Barbosa (2007), ao afirmar que os próprios alfabetizandos se reportam a imagens bastante negativas de si mesmos, e tais imagens refletiriam, no entendimento da autora, a reconstrução da identidade do alfabetizando adulto em meio a conflitos e tensões peculiares ao contexto de alfabetização e letramento.

Em (11) - "[...] tem de trabalhar sim, mas hoje eu me dou conta, que perdi tudo, que eu devia ter trabalhado menos e ter ligado o estudo com o trabalho" (MG., 2011) -, vemos evidenciado, novamente, o movimento de autoculpabilização, discutido na primeira parte deste artigo. Parece estar implicada, nesse movimento de autoculpabilização, uma autorresponsabilização pela continuidade dos 
estudos nessa etapa da vida e pela não evasão escolar. Assim, a participante de pesquisa não se vê como vítima de um construto social mais amplo, que acaba por impedir ou dificultar a permanência dela no processo de escolarização, mas sim como responsável tanto pela desistência como pela permanência no processo, mais uma vez o universo a que faz menção Britto (2004).

Assim, ao contrário do que se poderia esperar, as motivações dessas participantes de pesquisa não têm relação biunívoca com ascensão econômica e profissional, como sinalizam os objetivos definidos para o Curso - cf. terceira seção deste artigo. Perpassam tais motivações, antes, questões de foro íntimo, individual (KLEIMAN, 2001) - representação favorável do processo primeiro de escolarização ainda na infância e que inculca nos sujeitos uma vontade de retorno à escola que perpassa a vida toda, ou a busca por algumas horas de relaxamento -, e de foro externo, social (KLEIMAN, 2001) - vivência estrita com alfabetizado, anseio por potencialização das habilidades interacionais e do repertório lexical e gramatical. As implicações econômicas e profissionais do reingresso escolar parecem ser secundárias e, seguramente, demandam trabalhos com esse enfoque.

\section{Considerações finais}

Embora não se trate de um estudo em que os dados são facilmente depreensíveis e analisáveis, entendemos que trabalhos deste tipo podem contribuir para a compreensão das motivações dos alfabetizandos adultos diante do processo de reinserção escolar. Com essa compreensão se coaduna, em nosso entendimento, em grande medida, a permanência dos(as) alfabetizandos(as) nas classes escolares, o que depende, por sua vez, de ações didático-pedagógicas sistemáticas que possam facultar, efetivamente, a horizontalização das práticas de uso da língua em contextos de sentido, eixo tanto do processo de alfabetização como do ensino de língua materna de modo geral.

Nesse sentido, importa que retomemos a questão que norteou nosso estudo: o que motiva as mulheres envolvidas neste estudo a recorrerem a uma instituição escolar a fim de participarem de um programa de alfabetização? O anseio por retorno à escola por parte delas parece tê-las acompanhado ao longo de toda a vida, no que vemos implicada uma representação favorável do processo primeiro de inserção escolar. O abandono da escola, naquele momento de suas vidas, parece suscitar um movimento de culpabilização atribuída a diferentes agentes que não os sociais mais amplos. Figuram, entre as participantes, motivações de foro íntimo, individual (KLEIMAN, 2001) - representação favorável do processo primeiro de escolarização ainda na infância e que inculca nos sujeitos uma vontade de retorno à escola que perpassa a vida toda, ou a busca por algumas horas de relaxamento -, e 
de foro externo, social (KLEIMAN, 2001) - vivência estreita com alfabetizado, anseio por potencialização das habilidades interacionais e do repertório lexical e gramatical. As implicações econômicas e profissionais do reingresso escolar, ainda que presentes, parecem ser secundárias.

Quando analisadas, então, as principais motivações dessas mulheres na busca por programas de alfabetização institucionalizados, elas parecem ter natureza bem mais imediata e prática do que o que intentam os idealizadores dos programas, isto é, ampliar os recursos expressivos a fim de poder interagir com pessoas de outros grupos sociais; ou, ainda, aprimorar ou passar a dominar escrita, leitura e cálculo, dentre outros (GALVÃO; DI PIERRO, 2007).

Muitas dessas iniciativas governamentais, no entanto, frequentemente fracassam por assumirem perspectivas de aprendizagem homogêneas e sobrepostas, além de incompatíveis com esses interesses e necessidades das pessoas adultas. Street (2003) defende que, antes de serem empregados, os programas e as intervenções em alfabetização devem compreender as práticas de letramento em que já estejam envolvidos os grupos e as comunidades.

Uma alternativa promissora, no sentido da eficiência dos programas, é a sua elaboração “[...] a partir das práticas culturais próprias dos grupos que deles participam, que focalizam tipos particulares e situados de conhecimentos, de identidades e modelos de ação" (VÓVIO, 2010, p. 101). Assim, é preciso, antes, entender as práticas de uso da escrita como algo necessariamente plural, porque "[...] sociedades diferentes e grupos sociais que as compõem têm variadas formas de letramento, tendo a escrita tantos efeitos qualitativos sobre os sujeitos quanto possibilidades e funções que assume para eles em contextos sociais específicos" (VÓVIO, 2010, p. 101).

\section{Notas}

${ }^{1}$ Cabe ressalvar as razões de nossa remissão ao longo deste artigo à alfabetização e não ao letramento: compreendemos que letramento, assumido como fenômeno social que transcende a escolarização, não é passível de ensino tal qual se dá no espaço escolar; neste espaço, tanto os Anos Iniciais quanto o I Segmento, no caso deste estudo, têm como especificidade o ensino do Sistema de Escrita Alfabética (SEA) nos e para os usos sociais da escrita, processo que não se dá apartado do fenômeno do letramento, é continente nele, mas não pode ser tomado como sinônimo de tal fenômeno (KLEIMAN, 1995; CERUTTI-RIZZATTI, 2009).

${ }^{2}$ A Educação de Jovens e Adultos é modalidade de ensino regulamentada pela Lei de Diretrizes e Bases (LDB), Lei n. 9.394 , de 20 de dezembro de 1996 .

${ }^{3}$ M. Entrevista I. [7 ago. 2011]. Entrevistadora: Rosângela Pedralli. Florianópolis, 2011. 1 arquivo .mp3 em posse das autoras. As demais menções à M. utilizadas neste artigo dizem respeito à entrevista em questão.

${ }^{4}$ E. Entrevista II. [12 ago. 2011]. Entrevistadora: Rosângela Pedralli. Florianópolis, 2011. 1 arquivo .mp3 em posse das autoras. As demais menções à E. utilizadas neste artigo dizem respeito à entrevista em questão.

${ }^{5}$ MG. Entrevista III. [12 ago. 2011]. Entrevistadora: Rosângela Pedralli. Florianópolis, 2011.1 arquivo .mp3 em posse das autoras. As demais menções à MG. utilizadas neste artigo dizem respeito à entrevista em questão.

${ }^{6}$ Uma discussão pormenorizada dessas práticas pode ser encontrada em Pedralli (2011; 2012a; $\left.2012 \mathrm{~b}\right)$. 


\section{REFERÊNCIAS}

BARBOSA, Maria Lúcia Ferreira de Figueirêdo. A construção da identidade de alfabetizadoras em formação. In: LEAL, Telma Ferraz; ALBUQUERQUE, Eliana Borges Correia de (Orgs.). Desafios da educação de jovens e adultos: construindo práticas de alfabetização. 1 ed. Belo Horizonte: Autêntica, 2007, p. 49-70.

BRITTO, Luiz Percival Leme. Inquietudes e desacordos: a leitura além do óbvio. Campinas, SP: Mercado de Letras, 2012.

Sociedade de cultura escrita, alfabetismo e participação. In: RIBEIRO, Vera Massagão. Letramento no Brasil: reflexões a partir do INAF 2001. 2 ed. São Paulo: Global, 2004, p. 47-64. 2003.

Contra o consenso: cultura escrita, educação e participação. Campinas, SP: Mercado de Letras,

CERUTTI-RIZZATTI, Mary Elizabeth. Letramento: um conceito em (des)construção e suas implicações/repercussões na ação docente em língua materna. Fórum Linguístico, Florianópolis, v. 6, n. 2, p.1-15, jul./dez. 2009.

E. Entrevista II. [12 ago. 2011]. Entrevistadora: Rosângela Pedralli. Florianópolis, 2011. 1 arquivo .mp3 em posse das autoras.

FLORIANÓPOLIS. Informações gerais sobre a EJA. Prefeitura Municipal de Florianópolis, Florianópolis, 22 fev. 2010. Disponível em: <http://www.pmf.sc.gov.br/arquivos/arquivos/pdf/22_02_2 010_8.58.54.df4e8c71110b920b69b35009af5abac5.pdf>. Acesso em: 9 set. 2017.

FLORANÓPOLIS. Conselho Municipal de educação. Resolução no 2, de 13 de dezembro de 2010 b. Estabelece Normas Operacionais Complementares em conformidade com o Parecer CNE/CEB $n^{\circ}$ 06/2010, Resoluções CNE/CEB no 02/2010 e n 04/2010, que instituem as Diretrizes Gerais e Operacionais para a Educação de Jovens e Adultos. Prefeitura Municipal de Florianópolis, Florianópolis, 11 maio 2011. Disponível em: <http://www.pmf.sc.gov.br/arquivos/arquivos/pdf/11_05_ 2011_12.08.55.735d2fbf7f7260f583b585211b7bdf60.pdf>. Acesso em: 9 set. 2017.

GALVÃO, Ana Maria de Oliveira; DI PIERRO, Maria Clara. Preconceito contra o analfabeto. São Paulo: Cortez, 2007.

GRAFF, Harvey J. Os labirintos da alfabetização: reflexão sobre o passado e o presente da alfabetização. Porto Alegre: Artes Médicas, 1994.

KALMAN, Judith. El acesso a la cultura escrita: la participación social y lla apropiación de conocimientos em eventos cotidianos de lectura y escritura. Revista Mexicana de Investigación Educativa, v. 8, n. 17, p. 37-66, jan./abr. 2003. 
KLEIMAN, Angela B. Modelos de letramento e as práticas de alfabetização na escola. In: Os significados do letramento: uma nova perspectiva sobre a prática da escrita. Campinas, SP: Mercado dos Letras, 2001, p. 15-64.

KLEIMAN, Angela B. Programas de educação de jovens e adultos e pesquisa acadêmica: a contribuição dos estudos do letramento. Educação e Pesquisa, São Paulo, v. 27, n. 2, p. 267-281, jul./dez. 2001.

MACIEL, Francisca Izabel Pereira; LUCIO, Iara Silva. O analfabeto e o alfabetizado: a leitura e a escrita como atividades socialmente situadas. In: MARINHO, Marildes; CARVALHO, Gilcinei Teodoro (Org.). Cultura escrita e letramento. Belo Horizonte: UFMG, 2010.

M. Entrevista I. [7 ago. 2011]. Entrevistadora: Rosângela Pedralli. Florianópolis, 2011. 1 arquivo .mp3 em posse das autoras.

MG. Entrevista III. [12 ago. 2011]. Entrevistadora: Rosângela Pedralli. Florianópolis, 2011. 1 arquivo .mp3 em posse das autoras.

PEDRALLI, Rosângela. Usos sociais da escrita empreendidos por adultos alfabetizandos em programa educacional institucionalizado: dimensões extraescolar e escolar. 2011. 292f. Dissertação (Mestrado em Linguística) - Universidade Federal de Santa Catarina, Florianópolis, 2011.

. Usos sociais da escrita em espaço escolar: as relações estabelecidas por mulheres inseridas em turma de primeiro segmento da EJA. Fórum Linguístico, Florianópolis, v. 9, n. 2, p. 128-144, abr./jun. 2012a.

- Uso da escrita no cotidiano: uma análise a partir dos eventos de letramento dos quais participam três mulheres inseridas em turma de primeiro segmento da EJA. Working Papers em Linguística (Impresso), v. 13, p. 21-40, 2012 b.

PEDRALLI, Rosângela; CERUTTI-RIZZATTI, Mary Elizabeth. Evasão escolar na educação de jovens e adultos: problematizando o fenômeno com enfoque na cultura escrita. Revista Brasileira de Linguística Aplicada, Belo Horizonte, v. 13, n. 3, p. 771-788, 2013.

PONZIO, Augusto. (Cura) Globalizazione e infunzionalità. Athanor. Tradução: Mary Elizabeth Cerutti-Rizzatti. Roma: Maltemi, 2008-09. p. 21-41.

Procurando uma palavra outra. São Carlos: Pedro \& João, 2010.

STREET, Brian. Abordagens alternativas ao letramento e desenvolvimento. Apresentado durante a Teleconferência Unesco Brasil sobre 'Letramento e Diversidade', outubro de 2003.

. Literacy in theory and practice. Cambridge: CUP, 1984.

STROMQUIST, Nelly P. Convergências e divergências na conexão entre gênero e letramento: novos avanços. Educação e Pesquisa, São Paulo, v. 27, p. 301-320, jul./dez. 2001. 
VIGOTSKI, Lev Semenovich. A formação social da mente. São Paulo: Martins Fontes, 2007.

VÓVIO, Cláudia Lemos. Outras perspectivas sobre a alfabetização de pessoas de jovens e adultos. In: SERRANI, Silvana (Org.). Letramento, discurso e trabalho docente. Vinhedo, Horizonte, 2010. p. 100-115. 
The women's insertion in alphabetization program: students motivations

\begin{abstract}
Is objective of this article motivations in relation to the formal alphabetization process explicit by woman inserted in graphocentric environment. The following question guided the study: What motivates the women participant in this study to call upon a scholastic institution to participate of an alphabetization program?. Theoretically this work, a study case of ethnographic kind, is based on Graff (1994), Britto (2003; 2004), Stromquist (2005), among others. The results point to a convergence between the purposes of these programs and that motivations.
\end{abstract}

Keywords: Alphabetization. Young and Adult Education. Motivations.

\section{Rosângela Pedralli}

E-mail: rosangelapedralli@hotmail.com

\section{Laiana Abdala Martins}

E-mail: laiana_abdala@hotmail.com

\section{La inserción de mujeres en programa de alfabetización: motivaciones de estudiantes}

\section{Resumen}

El objeto de este artículo incluye las motivaciones de mujeres inseridas en entornos grafocêntricos, en relación al proceso de alfabetización formal. Orienta este estudio la siguiente pregunta: ¿Qué motiva a las mujeres que participan de este estudio para hacer uso de una institución escolar con el fin de participar en un programa de alfabetización? Teóricamente la base de este trabajo, un estudio de caso de tipo etnográfico, Graff (1994), Britto (2003; 2004), Stromquist (2005), entre otros. Los resultados apuntan a la convergência parcial entre los objetivos de estos programas y estas motivaciones.

Palabras clave: Alfabetización. Educación de Jóvenes y Adultos. Motivaciones.

Enviado em: 12/09/2015

Versão final recebida em:

Aprovado em: 22/12/2016 